\title{
The insect, Galleria mellonella, is a compatible model for evaluating the toxicology of okadaic acid
}

\author{
Christopher J. Coates 10 - Jenson Lim • \\ Katie Harman • Andrew F. Rowley • \\ David J. Griffiths • Helena Emery • Will Layton
}

Received: 28 July 2018 / Accepted: 4 October 2018 / Published online: 13 November 2018

(C) The Author(s) 2018

\begin{abstract}
The polyether toxin, okadaic acid, causes diarrhetic shellfish poisoning in humans. Despite extensive research into its cellular targets using rodent models, we know little about its putative effect(s) on innate immunity. We inoculated larvae of the greater wax moth, Galleria mellonella, with physiologically relevant doses of okadaic acid by direct injection into the haemocoel (body cavity) and/or gavage (force-feeding). We monitored larval survival and employed a range of cellular and biochemical assays to assess the potential harmful effects of okadaic acid. Okadaic acid at concentrations $\geq 75 \mathrm{ng} /$ larva $(\geq 242 \mu \mathrm{g} / \mathrm{kg}$ ) led to significant reductions in larval survival $(>65 \%)$ and circulating haemocyte (blood cell) numbers $(>50 \%)$ within $24 \mathrm{~h}$ post-inoculation. In the haemolymph, okadaic acid reduced haemocyte viability and increased phenoloxidase activities. In the midgut, okadaic acid induced oxidative damage as determined by increases in superoxide dismutase activity and levels of malondialdehyde (i.e. lipid peroxidation). Our observa-
\end{abstract}

Electronic supplementary material The online version of this article (https://doi.org/10.1007/s10565-018-09448-2) contains supplementary material, which is available to authorized users.

C. J. Coates $(\bowtie) \cdot$ K. Harman · A. F. Rowley •

D. J. Griffiths · H. Emery • W. Layton

Department of Biosciences, College of Science, Swansea

University, Swansea, Wales SA2 8PP, UK

e-mail: c.j.coates@swansea.ac.uk

J. Lim

Biological and Environmental Sciences, Faculty of Natural

Sciences, University of Stirling, Stirling, Scotland FK9 4LA, UK tions of insect larvae correspond broadly to data published using rodent models of shellfish-poisoning toxidrome, including complementary $\mathrm{LD}_{50}$ values: $206-242 \mu \mathrm{g} / \mathrm{kg}$ in mice, $\sim 239 \mu \mathrm{g} / \mathrm{kg}$ in G. mellonella. These data support the use of this insect as a surrogate model for the investigation of marine toxins, which offers distinct ethical and financial incentives.

Keywords Haemocytes - Innate immunity - Oxidative stress $\cdot$ Phenoloxidase $\cdot$ Shellfish-poisoning syndrome . Immunotoxicology

$\begin{array}{ll}\text { Abbreviations } \\ \text { DSP } & \text { Diarrhetic shellfish poisoning } \\ \text { OA } & \text { Okadaic acid } \\ \text { PBS } & \text { Phosphate-buffered saline } \\ \text { MDA } & \text { Malondialdehyde } \\ \text { PO } & \text { Phenoloxidase } \\ \text { SDS } & \text { Sodium dodecyl sulphate } \\ \text { SOD } & \text { Superoxide dismutase }\end{array}$

\section{Introduction}

Diarrhetic shellfish poisoning (DSP) is one of several recognised shellfish-poisoning syndromes including amnesic, neurotoxic, and paralytic. Upon consumption of bivalves, crustaceans, sea urchins, and finfish contaminated with the polyether toxin, okadaic acid $\left(\mathrm{C}_{44} \mathrm{H}_{68} \mathrm{O}_{13}\right)$, DSP manifests as nausea, vomiting, diarrhoea, abdominal cramps, and chills (Vale and 
Sampayo 2002; Valdiglesias et al. 2013). These symptoms tend to develop within $4 \mathrm{~h}$ of intoxication and can last for several days. Okadaic acid (OA) and its derivatives (DTXs 1-3) are produced mainly by the dinoflagellate genera, Prorocentrum and Dinophysis, and $<50 \mu \mathrm{g}$ per kg contaminated shellfish tissue can induce symptoms of DSP in humans (Dominguez et al. 2010). In addition to being a potent inhibitor of serinethreonine phosphatases, OA is a tumour promoter with genotoxic and neurotoxic properties (Munday 2013). The occurrences of harmful algal blooms and the incidences of human intoxication from contaminated shellfish are predicted to increase annually due to climate change (Gobler et al. 2017). This represents a significant health concern for the public and additional financial burden for the aquaculture and fishing industries (Gobler et al. 2017).

The coastal waters surrounding the UK are considered a potential hot spot for Dinophysis species blooms and the concomitant release of DSP-associated toxins. Moreover, between 1999 and 2009, DSP blighted UK shellfish harvesters with 19 outbreaks recorded-the most of any shellfish-poisoning toxin (Hinder et al. 2011). That said, the acute or chronic impacts of lipophilic phytotoxins, including pectenotoxins and azaspiracids, on immune functionality are poorly understood. The traditional method for screening contaminated shellfish was the mouse bioassay (Yasumoto et al. 1985), but this has been replaced within the last decade by analytical methods. Such approaches are limited to screening only and do not offer insight into the mechanism(s) of action of OA. Therefore, we require a reliable in vivo model to explore in-depth the effects of OA at cellular and molecular levels.

Larvae of the greater wax moth, Galleria mellonella, have been developed to interrogate the pathogenicity of microbes (Lim et al. 2018), efficacy of novel biopharmaceuticals, and toxicity of diverse chemicals (Allegra et al. 2018; Maguire et al. 2016; Wuensch et al. 2018). In addition to their ease-of-use, low maintenance costs, and lack of legislative/ethical restrictions, the recent publication of the G. mellonella genome by Lange et al. (2018) should see their popularity increase as an alternative model to rodents. A biological advantage of using larvae is that the insect innate immune system is mechanistically similar to aspects of vertebrate innate immunity, e.g. antimicrobial peptide production, pathogen recognition via ligand interactions, and phagocyte-mediated respiratory burst (Bergin et al.
2005; Browne et al. 2013; Butt et al. 2016). We consider the applicability of $G$. mellonella larvae as an in vivo system can extend to screening the harmful effects of known, and emerging, marine toxins that confront commercially important shellfish and humans.

The overall aim of our study was to carry out an assessment on the relative toxicity of OA in an alternative model. To address this, we prospected the larvae of G. mellonella to compare (1) $\mathrm{LD}_{50}$ values in insects with those available from rodents, (2) two inoculation methodologies (intrahaemocoelic injection versus forcefeeding), and (3) the cellular and biochemical responses to physiologically relevant doses of OA (25-125 ng/ larva $=80.65-403.25 \mu \mathrm{g} / \mathrm{kg}$ ). We arrived at this concentration range by selecting values above and below the upper regulatory limit set by the Food Standards Agency $\mathrm{UK}$, which is $160 \mu \mathrm{g}$ OA per $\mathrm{kg}$ contaminated shellfish tissue (FSA 2018).

\section{Materials and methods}

\section{Reagents}

Unless stated otherwise, all reagents used in this study were of the highest purity available when purchased from Sigma-Aldrich (Dorset, UK). Certified okadaic acid $\left(\mathrm{OA} ; \mathrm{C}_{44} \mathrm{H}_{68} \mathrm{O}_{13}\right)$ was sourced from TOCRIS Biosciences (UK; Cat. No. 1136).

\section{Insects}

Final instar larvae of the greater wax moth, Galleria mellonella, were sourced from Livefoods Direct (Sheffield, UK) and Pets at Home Ltd. (Cheshire, UK) or reared in-house following the guidelines proposed by Jorjão et al. (2018). Each insect was inspected for damage/infection and stored subsequently for no more than 7 days at $15^{\circ} \mathrm{C}$ in wood shavings provided by the commercial suppliers. Only healthy larvae weighing $0.31 \pm 0.04 \mathrm{~g}$ were used. Larvae were assigned randomly to each treatment and all experiments were performed on at least three independent occasions.

\section{Survival studies $\left(\mathrm{LD}_{50}\right)$}

Insects were inoculated via intrahaemocoelic injection (26/27-gauge needle) through the last left pro-leg with $20 \mu \mathrm{L}$ of increasing concentrations of OA: $25,50,75$, 
100, and 125 ng per larva. Stock concentrations of OA were prepared in dimethyl sulfoxide (DMSO, Cat. No. D8418) and diluted to working concentrations in $(0.2 \mu \mathrm{m})$ filter-sterilised phosphate-buffered saline (PBS, Cat No. P4417) pH 7.4 prior to injection. Negative controls consisted of PBS only $(20 \mu \mathrm{L})$ or PBS containing 5\% DMSO $(20 \mu \mathrm{L})$. Post-inoculation, larvae were placed in 90-mm petri dishes containing Whatman filter paper and wood shavings and incubated at $30^{\circ} \mathrm{C}$ in the dark. Survival was recorded over a $96-\mathrm{h}$ period.

As OA exposure is via the ingestion of contaminated shellfish tissues, we compared inoculation methods. In a second experiment, insect larvae (reared in-house) were either injected (described above) or force-fed (gavage) $\mathrm{OA}$ at 25, 75, and $125 \mathrm{ng} / \mathrm{larva}$. On each occasion, it was administered using a 27-gauge hypodermic needle and survival was recorded over a 72 -h period.

Cellular analyses of larvae injected with OA

\section{Total haemocyte counts}

Approximately $50 \mu \mathrm{L}$ of haemolymph was extracted from challenged (OA) and control (PBS) larvae by piercing the insect integument with a 26/27-gauge hypodermic needle and pooling samples from two individuals at each time point (4, 24, and 48 h). Haemolymph was collected into pre-chilled (sterile) microcentrifuge tubes, diluted into PBS pH 7.4, and enumerated using an improved Neubauer haemocytometer.

\section{Cytological staining}

Extracted haemolymph $(10 \mu \mathrm{L})$ was mixed immediately in a ratio of $1: 1$ with PBS pH 7.4 containing $0.2 \%$ trypan blue ( $w / v$, Cat. No. T6146) for determining cellular viability. Samples were incubated for no more than $3 \mathrm{~min}$ at room temperature prior to counting. Trypan blue-positive (non-viable) versus un-stained (viable) haemocytes were used to calculate percentage mortality.

Phenoloxidase (PO)-positive haemocytes were identified using a staining method adapted from Aladaileh et al. (2007). Briefly, haemolymph $(10 \mu \mathrm{L})$ was mixed with an equal volume of PBS containing $5 \mathrm{mM} \mathrm{MBTH}$ (3-methyl-2-benothiazolinone hydrazine, Cat. No. 129739), $4 \mathrm{mM}$ dopamine hydrochloride (Cat. No. H8502), 4-HA (methoxyphenol, Cat. No. 54050), and $20 \mu \mathrm{g} \mathrm{mL}^{-1}$ lipopolysaccharides from Escherichia coli (Cat. No. L2630). Samples were incubated for $30 \mathrm{~min}$ at room temperature before being examined under brightfield optics. Haemocytes staining positively for PO appeared reddish brown in colour.

All haemocyte observations were performed in duplicate (two technical replicates per biological replicate). Fields of view were selected randomly until 200 to 300 cells were counted per sample.

Biochemical analyses of insects inoculated with OA

All assays were performed in a SPECTROstar Nano using either the cuvette port ( $1 \mathrm{~mL}$ volume) or 96-well plate reader $(\sim 250 \mu \mathrm{L}$ volume). In each case, protein concentrations of cell-free haemolymph and midgut homogenates were determined using the Biuret method with bovine serum albumin (Cat. No. A2153) as a standard.

\section{Phenoloxidase activity in insects after OA injection or gavage}

Haemolymph samples were removed from control (PBS) and OA-treated larvae (over a 48-h period) and centrifuged at $1000 \times g$ for 2 min to remove haemocytes. Supernatants were retained and placed on ice. Background absorbance readings of each reaction mixture (in the absence of haemolymph) were subtracted from final readings. Each enzyme assay $(1 \mathrm{~mL})$ was carried out at $28^{\circ} \mathrm{C}$ in PBS pH 7.4 containing $2 \mathrm{mM}$ dopamine hydrochloride (substrate) and cell-free haemolymph diluted 1:100 $(v / v)$. PO activity was calculated by monitoring an increase in absorbance at $475 \mathrm{~nm}$ due to the formation of product (i.e. dopaminechrome) over a 10min period. One unit of PO activity is defined as the increase in absorbance at $475 \mathrm{~nm}$ per minute per $\mathrm{mg}$ protein.

\section{REDOX-associated activity in the insect midgut after force-feeding $O A$}

Six insect larvae per treatment per time point were chilled on ice for $5 \mathrm{~min}$ and dissected to remove the midgut. These samples were pooled to represent a single biological replicate. Dissections were performed in filter-sterilised PBS pH 7.4 and homogenised using $0.1 \mathrm{~g}$ midgut tissues in $1 \mathrm{~mL}$ PBS or malondialdehyde (MDA) lysis solution. Homogenates were centrifuged at $13,000 \times g$ for $10 \mathrm{~min}$ at $4{ }^{\circ} \mathrm{C}$ to remove cellular debris prior to freezing the supernatants at $-80{ }^{\circ} \mathrm{C}$. 


\section{Superoxide dismutase activity}

Activity of the enzymatic antioxidant, superoxide dismutase (SOD) (EC 1.15.1.1), was detected spectrophotometrically at $560 \mathrm{~nm}$ using a colorimetric kit (Cat. No. ab65354) purchased from Abcam (Cambridge, UK). Water-soluble tetrazolium salts (WST-1) produce a formazan dye when reduced by superoxide anions $\left(\mathrm{O}_{2}{ }^{-}\right)$. This rate of reduction shares a linear relationship with the activity of xanthine oxidase, which is inhibited by SOD. Therefore, SOD activity was calculated based on its ability to inhibit the reduction of WST-1. Assays consisted of $20 \mu \mathrm{L}$ midgut homogenate, $20 \mu \mathrm{L}$ enzyme working solution (xanthine oxidase), and $200 \mu \mathrm{L}$ WST working solution (following supplier's guidelines). Sample mixtures were incubated at $28{ }^{\circ} \mathrm{C}$ for $20 \mathrm{~min}$ prior to data collection. One unit of SOD activity is expressed as the increase in absorbance at $560 \mathrm{~nm}$ per minute per mg protein.

\section{Lipid peroxidation-malondialdehyde accumulation}

Oxidative deterioration of lipids was detected spectrophotometrically using a colorimetric kit (Cat. No. ab118970) from Abcam (Cambridge, UK). Briefly, midgut samples washed with PBS pH 7.4 were processed in MDA lysis solution. Sample homogenates $(\sim 200 \mu \mathrm{L})$ were added to $600 \mu \mathrm{L}$ thiobarbituric acid reagent and incubated at $95^{\circ} \mathrm{C}$ for $1 \mathrm{~h}$ prior to data collection. Lipid peroxidation was recorded as the increase in absorbance at $532 \mathrm{~nm}$ per minute per $\mathrm{mg}$ protein. Absorbance values were converted to concentrations (nmol) of MDA using the molar coefficient $1.56 \times 10^{5} \mathrm{M}^{-1} \mathrm{~cm}^{-1}$ and confirmed using the standard curve recommended by the supplier.

\section{Data handling}

All survival experiments consisted of a minimum 30 individuals per treatment (10 larvae per independent replicate). Results from survival experiments $(n=30$ 70 per treatment, 300-490 in total) were analysed in GraphPad Prism 7.0 using the log-rank (Mantel-Cox) test (curve comparisons). We further assessed insect survival between the two inoculation methods using a three-way ANOVA: OA doses [25, 75, $125 \mathrm{ng}]$, time [24, $72 \mathrm{~h}$ ], inoculation [injection/gavage]. $\mathrm{LD}_{50}$ values for $\mathrm{OA}$ were calculated at $24 \mathrm{~h}$ post-inoculation by fitting data to a dose-response curve $[\log 10($ dose $)]$ with four parameters (min, max, $\mathrm{EC}_{50}$, slope of the curve). Cellular and biochemical properties of the insects challenged with okadaic acid were analysed $(n=18-54$, 108-270 in total) using two-way ANOVA with Tukey's multiple comparison tests. Differences were considered significant when $P \leq 0.05$.

\section{Results}

Relative toxicity of OA in insect larvae

Intrahaemocoelic injection of OA had a significant negative effect on the survival of G. mellonella larvae (logrank (Mantel-Cox) curve comparison test: $\chi^{2}(6)=$ 208.2, $P<0.0001$; Fig. 1a, b). As the dose of OA increased, we observed more pronounced melanisation/darkening of the insect cuticle and discolouration was also reflected in the haemolymph (Fig. 1c). Analysis of the survival curves revealed no significant differences (log-rank (Mantel-Cox), $\chi^{2}(1)=$ 1.04, $P=0.3078$ ) between PBS and PBS $+5 \%$ DMSO over the $96-\mathrm{h}$ period. As the toxin was lethal within $24 \mathrm{~h}$ post-inoculation using the concentration range of 25$125 \mathrm{ng} /$ larva (equivalent to $80.65-403.25 \mu \mathrm{g}$ [okadaic acid] per $\mathrm{kg}$ [tissue]), we calculated an $\mathrm{LD}_{50}$ value of $239.55 \mu \mathrm{g} / \mathrm{kg}\left[R^{2}=0.951\right]$ at this time point (Fig. 1a). This falls within the range of $\mathrm{LD}_{50}$ values calculated for OA administered via intraperitoneal injection in the mouse bioassay (Table 1). Survival across all treatments was $100 \%$ up to $4 \mathrm{~h}$ post-injection.

Doses of OA in excess of $50 \mathrm{ng} /$ larva reduced survival substantially from $74 \%$ to $41-27 \%(75-125 \mathrm{ng} /$ larva) at $24 \mathrm{~h}$. Hazard ratios (Mantel-Haenszel) of 3.11 (95\% CI, 1.73-5.62), 4.34 (95\% CI, 2.41-7.80), and 6.48 (95\% CI, 3.63-11.55) were calculated for the increases in $\mathrm{OA}$ from 50 to 75,100 , and $125 \mathrm{ng} /$ larva, respectively (see Supplementary Table 1 for all pairwise comparisons).

Effect of OA on cellular and biochemical properties of Galleria mellonella

Changes in haemocyte numbers within insects can be used to gauge the immune-suppressive or immune-stimulatory effects of diverse compounds, including toxins (Mowlds et al. 2010; Fallon et al. 2011; Browne et al. 2013; Champion et al. 2016). When injected directly into the haemocoel, OA led to 

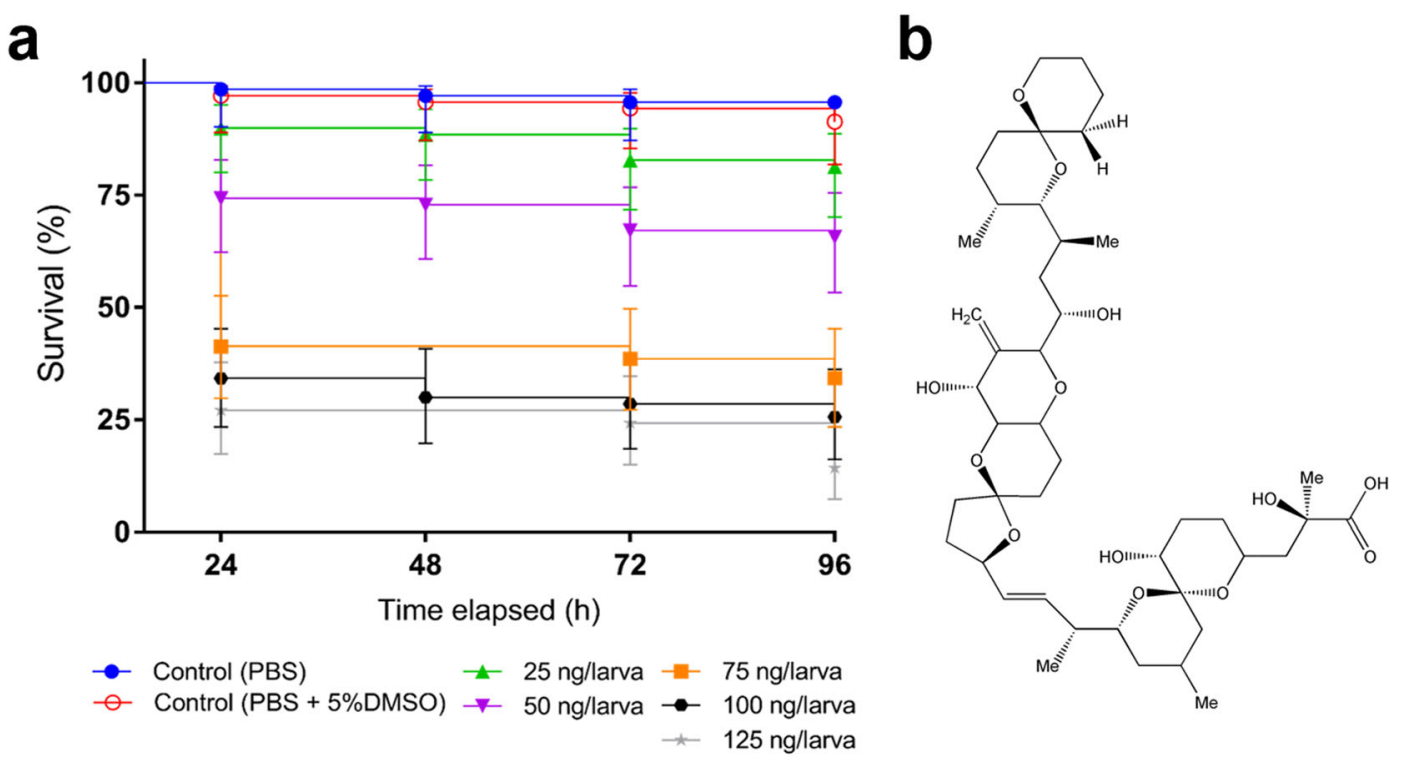

C
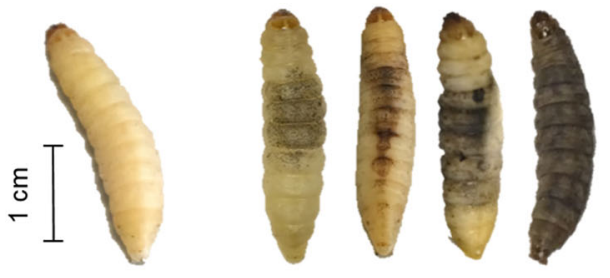

Healthy

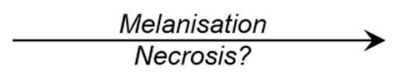

Fig. 1 a Survival of Galleria mellonella larvae following intrahaemocoelic injection of okadaic acid, 0-125 ng/larva. Postinjection of the biotoxin, larvae were incubated at $30^{\circ} \mathrm{C}$ in the dark and monitored over a 96-h period. Larvae unresponsive to touch were considered dead. Negative control groups consisted of larvae treated with $20 \mu \mathrm{L}$ phosphate-buffered saline (PBS) or $20 \mu \mathrm{L}$ PBS

significant reductions in circulating haemocyte numbers in a time $(F(2,116)=21.19, P<0.0001)$ and dose $(F(7,116)=47.31, P<0.0001)$ dependent manner (Fig. 2a). Within 4 h p.i., haemocyte numbers decreased from $3.5 \times 10^{7} \mathrm{~mL}^{-1}$ in the PBS control to $2.1-1.4 \times 10^{7} \mathrm{~mL}^{-1}$ in treatments $\geq$ $75 \mathrm{ng} /$ larva. Haemocyte numbers continued to fall in treatments $\geq 75 \mathrm{ng} /$ larva with $2.8-1.8 \times 10^{6} \mathrm{~mL}^{-1}$ remaining by $48 \mathrm{~h}$. Overall, time accounted for $\sim 9 \%$ of the variation within the data, whereas dosage accounted for $70.4 \%$. Haemocyte numbers within the control larvae remained unchanged for the duration of the experiment, ranging from $\sim 3$ to $3.5 \times$ $10^{7} \mathrm{~mL}^{-1}$ (Fig. 2a).
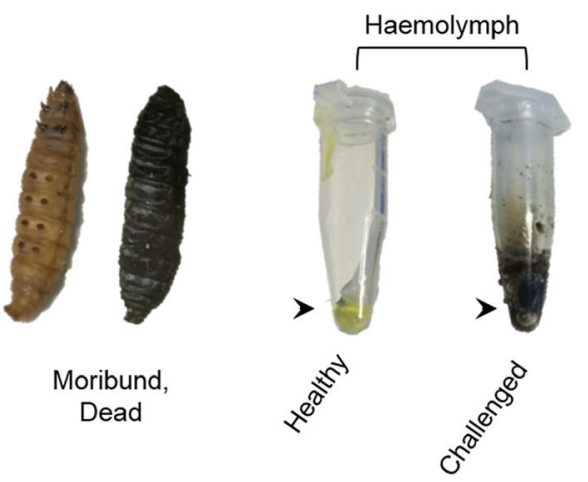

containing 5\% dimethyl sulfoxide (DMSO). All values are represented by the mean with $95 \% \mathrm{CI}(n=70$ per treatment, 490 in total). b Chemical structure of okadaic acid $\left(\mathrm{C}_{44} \mathrm{H}_{68} \mathrm{O}_{13}\right)$ from the dinoflagellate Prorocentrum concavum. c Images depicting varied melanisation reactions and haemolymph discolouration in healthy (yellow appearance) and challenged larvae

Using the trypan blue exclusion method, we determined $\mathrm{OA}$ to be cytotoxic to insect immune cells (Fig. 2b). Changes observed in trypan bluepositive (i.e. dead) haemocytes also occurred in a time $(F(2,48)=59.82, P<0.0001)$ and dose $(F(7$, $48)=51.71, P<0.0001)$ dependent manner (Fig. 2b-d). After the initial peak in cell death at $4 \mathrm{~h}$ p.i. wherein 31 to $68 \%$ of haemocytes ( 0.4 to $1.4 \times 10^{7} \mathrm{~mL}^{-1}$ ) were affected in larvae treated with 75-125 ng OA, trypan blue-positive haemocyte levels fluctuated subsequently between 10.5 and $38 \%$. Haemocyte deaths in control larvae did not drop below $4.8 \%$ or exceed $11 \%$ over the 48-h experimental period. 
Table 1 Okadaic acid administration, lethality, and pathobiology in animal models

\begin{tabular}{|c|c|c|c|c|}
\hline Model system & Administration & Lethality & Pathobiology & Reference \\
\hline Insect larvae [Galleria mellonella] & $\begin{array}{l}\text { Gavage } \\
\quad \text { (force-feeding) }\end{array}$ & $\begin{array}{l}\mathrm{LD}_{50}=248.3 \mu \mathrm{g} / \mathrm{kg}^{\mathrm{a}} \\
\quad\left[R^{2}=0.947, n=30\right]\end{array}$ & $\begin{array}{l}\text { Oxidative damage in the } \\
\text { midgut - increased SOD activity } \\
\text { and levels of MDA }\end{array}$ & This study \\
\hline Insect larvae [Galleria mellonella] & $\begin{array}{l}\text { Intrahaemocoelic } \\
\text { injection }\end{array}$ & $\begin{array}{l}\mathrm{LD}_{50}=239.55 \mu \mathrm{g} / \mathrm{kg}^{\mathrm{b}} \\
{\left[R^{2}=0.951, n=70\right]} \\
\mathrm{LD}_{50}=252.8 \mu \mathrm{g} /- \\
\mathrm{kg}_{\mathrm{a}}\left[R^{2}=0.900\right. \\
n=30]\end{array}$ & $\begin{array}{l}\text { Cytotoxicity - decreased haemocyte } \\
\text { numbers corresponding to } \\
\text { increased levels of cell death }\end{array}$ & This study \\
\hline Mouse bioassay (unknown strain) & $\begin{array}{l}\text { Intraperitoneal } \\
\text { injection }\end{array}$ & $\mathrm{LD}_{50}=206-229 \mu \mathrm{g} / \mathrm{kg}$ & $\begin{array}{l}\text { Small intestine and liver damage, } \\
\text { cyanosis }\end{array}$ & $\begin{array}{l}\text { Dickey et al. } \\
\text { (1990); } \\
\text { Tubaro et al. } \\
\text { (2003); Aune } \\
\text { et al. (2007) }\end{array}$ \\
\hline $\begin{array}{l}\text { Mice: A/J [inbred strain], BALB/c } \\
\text { [inbred strain], C3H/He [inbred } \\
\text { strain], C57BL/6 [inbred strain], } \\
\text { DBA/2 [inbred strain], ICR } \\
\text { [non-inbred] }\end{array}$ & $\begin{array}{l}\text { Intraperitoneal } \\
\text { injection }\end{array}$ & $\begin{array}{l}\text { Median lethal dose } \\
\quad 216-242.4 \mu \mathrm{g} / \mathrm{kg}\end{array}$ & Not available & Suzuki (2012) \\
\hline $\begin{array}{l}\text { Mice: ICR [non-inbred], NMRI } \\
\text { [inbred strain], Swiss mice }\end{array}$ & Gavage & $\begin{array}{l}\text { Median lethal dose } \\
\quad 300-880 \mu \mathrm{g} / \mathrm{kg}\end{array}$ & $\begin{array}{l}\text { Mild to severe damages to epithelial } \\
\text { villi in the duodenum, jejunum, } \\
\text { and caecum; bleeding and oedema } \\
\text { in the lung; apoptosis in the } \\
\text { kidney and liver }\end{array}$ & $\begin{array}{l}\text { Ito et al. (2002); } \\
\text { Le Hégarat } \\
\text { et al. (2006); } \\
\text { Aune et al. } \\
\text { (2012) }\end{array}$ \\
\hline Mouse (unknown strain) & $\begin{array}{l}\text { Dermal } \\
\text { application }\end{array}$ & Dose $80 \mathrm{ng}$ & $\begin{array}{l}\text { Severe irritation and tumour } \\
\text { promotion }\end{array}$ & $\begin{array}{l}\text { Fujiki et al. } \\
\text { (1987) }\end{array}$ \\
\hline Rat (unknown strain) & $\begin{array}{l}\text { Intrahippocampal } \\
\text { injection }\end{array}$ & Dose 7-70 ng/day & $\begin{array}{l}\text { Neuronal cell death, memory loss, } \\
\text { lipid peroxidation, protein } \\
\text { carbonylation }\end{array}$ & $\begin{array}{l}\text { He et al. (2001); } \\
\text { Zhang and } \\
\text { Simpkins } \\
(2010)\end{array}$ \\
\hline Rat [Wistar rats] & $\begin{array}{l}\text { Intravenous (tail) } \\
\text { injection }\end{array}$ & $\begin{array}{l}\text { Dose } 0.05-0.5 \mu \mathrm{g} / \mathrm{g} \\
\text { body weight }\end{array}$ & Blood congestion in the liver & $\begin{array}{l}\text { Berven et al. } \\
\quad(2001)\end{array}$ \\
\hline Rat [Nude rats] & $\begin{array}{l}\text { Gavage } \\
\quad \text { (intragastric } \\
\text { intubation) }\end{array}$ & $\begin{array}{l}\text { Dose } 1-4 \mu \mathrm{g} / \mathrm{g} \text { body } \\
\text { weight }\end{array}$ & $\begin{array}{l}\text { Damages to the small intestine, } \\
\text { shedding of epithelial cells, villus } \\
\text { fragmentation }\end{array}$ & $\begin{array}{l}\text { Berven et al. } \\
\text { (2001) }\end{array}$ \\
\hline
\end{tabular}

$M D A$, malondialdehyde; $S O D$, superoxide dismutase

${ }^{a}$ Insects reared in-house

${ }^{\mathrm{b}}$ Insects sourced commercially

Not only were there significantly fewer haemocytes overall within the haemolymph of OAtreated larvae (as low as $1.8 \times 10^{6} \mathrm{~mL}^{-1}$; Fig. 2a), but large proportions of them (up to $23 \%$ ) were dead at 48 h p.i. (Fig. 2b).

Melanisation of the insect haemolymph is a key response to the presence of infectious agents (microbes, viruses, or parasites), toxins, or abiotic stressors (Whitten and Coates 2017). The early enzymatic steps that contribute to melanin formation are coordinated by phenoloxidases (POs), which are stored as inactive precursors (proPO) inside certain haemocytes. We observed significant increases in PO activity in the haemolymph of insects challenged with OA (Fig. 3a). $\mathrm{PO}$ activity increased in a dose-dependent manner $(F(7$, $48)=29.46, P<0.0001)$ and fluctuated over time $(F(2$, $48)=24.95, P<0.0001)$. Product formation (dopaminechrome) peaked at $24 \mathrm{~h}$ p.i. with $0.39-0.69$ $\mathrm{Abs} / \mathrm{mg} / \mathrm{min}$ for OA-treated insects (25-125 ng/larva) compared to the controls (Fig. 3a). Although PO activities decreased by $48 \mathrm{~h}$ p.i. for all treatments, levels remained significantly higher for those insects exposed to $\geq 75 \mathrm{ng}$ of the toxin. PO activities in control and untouched larvae followed the same pattern as OA- 


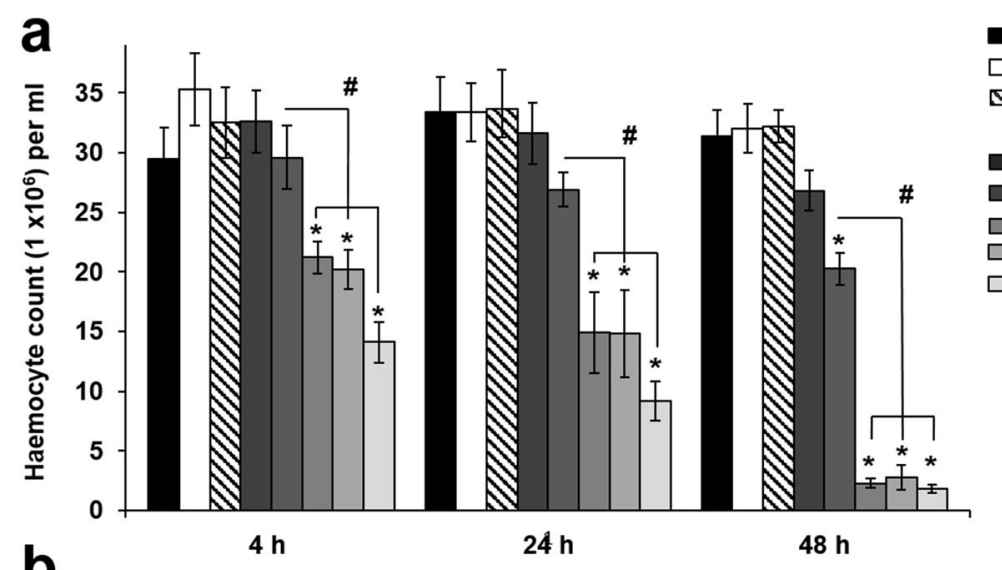

$$
\begin{aligned}
& \text { Untouched } \\
& \square \text { PBS } \\
& \square \text { PBS + 5\%DMSO }
\end{aligned}
$$
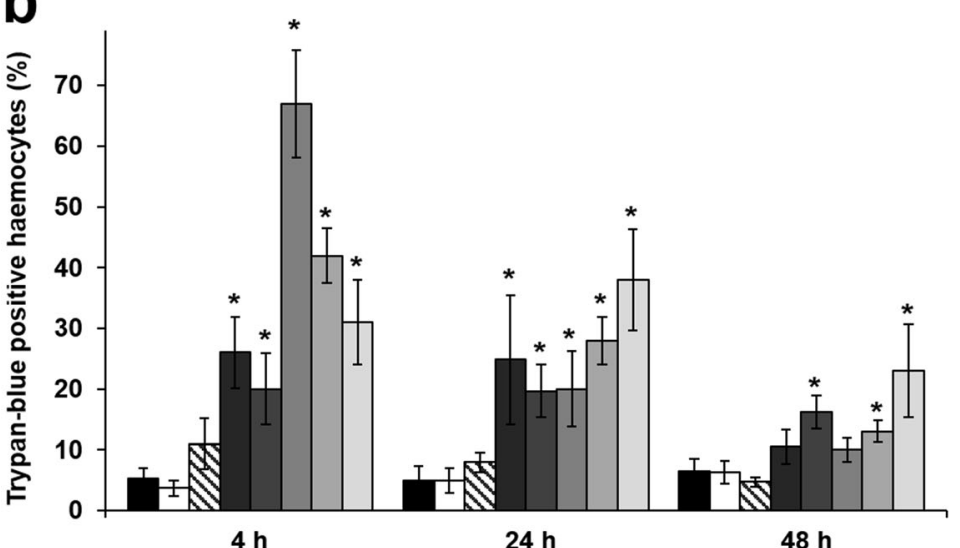

\section{$25 \mathrm{ng} / \mathrm{larva}$ $50 \mathrm{ng} / \mathrm{larva}$ $\square 75$ ng/larva $\square 100 \mathrm{ng} / \mathrm{larva}$ 125 ng/larva}

Okadaic acid
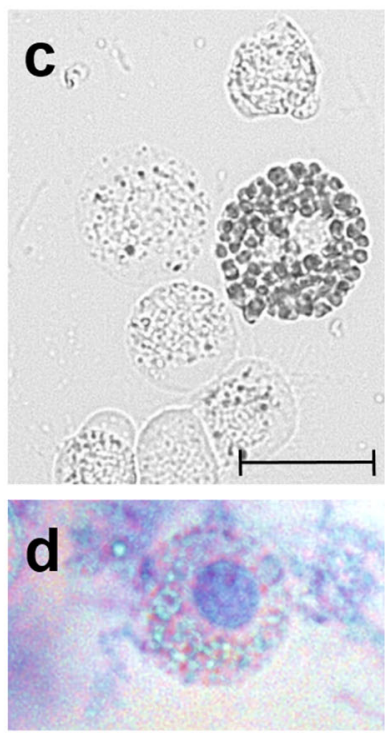

Fig. 2 Cellular properties of Galleria mellonella injected with increasing concentrations of okadaic acid, $0-125 \mathrm{ng}$ /larva. a Total haemocyte counts and $\mathbf{b}$ haemocyte viability using trypan blue exclusion were recorded over a 48 -h period. All values are represented by the mean $\pm \mathrm{SE}$ ( $n=18$ per treatment, 144 in total). An asterisk indicates a significant difference $(P<0.05)$ in haemocyte

numbers relative to the PBS control. A hashtag indicates significant differences between $50 \mathrm{ng} /$ larva and 75-125 ng/larva (determined by Tukey's multiple comparisons). c Image representing free-floating haemocytes. Scale bar represents $10 \mu \mathrm{m}$. d Dead (or dying) haemocytes stain blue

treated insects; however, activity remained lower at 0.067-0.196 Abs $/ \mathrm{mg} / \mathrm{min}$.

We used a PO-specific cellular stain to further explore the effect(s) of OA on haemocytes. As concentrations of the toxin increased, a corresponding decrease in the number of PO-positive haemocytes was observed (Fig. 3b, c). Although both time $(F(2,48)=100.8$, $P<0.0001)$ and dose $(F(7,48)=22.19, P<0.0001)$ of OA significantly affected numbers of PO-positive haemocytes, it was time that accounted for the majority of variation observed, $\sim 35 \%$. The number of POpositive haemocytes (Fig. 3b) correlated inversely to the increase in PO enzyme activities (Fig. 3a); therefore, we surmise that haemocytes are rupturing in the presence of OA and releasing PO into the haemolymph. Strikingly by $48 \mathrm{~h}$ p.i., $<0.01 \%$ of haemocytes stained positively for PO in larvae treated with $\geq 75 \mathrm{ng}$ toxin,

despite high levels of enzyme activity remaining detectable in the haemolymph. Conversely, the proportions of PO-positive haemocytes in the haemocoel of control and untouched larvae remained between 5.2 and $12.2 \%$ over the 48 -h period (Supplementary Table 2).

Toxicity of OA when administered using intrahaemocoelic injection versus force-feeding

Humans encounter OA when they consume contaminated shellfish; consequently, we investigated the relative toxicity of OA administered by force-feeding (gavage) compared to direct injection into the haemocoel (Fig. 4). We monitored the dissemination of tracer dye in insect larvae injected or force-fed a $20-\mu \mathrm{L}$ inoculum. The inoculum dispersed immediately throughout the haemocoel (body cavity) when injected through the 


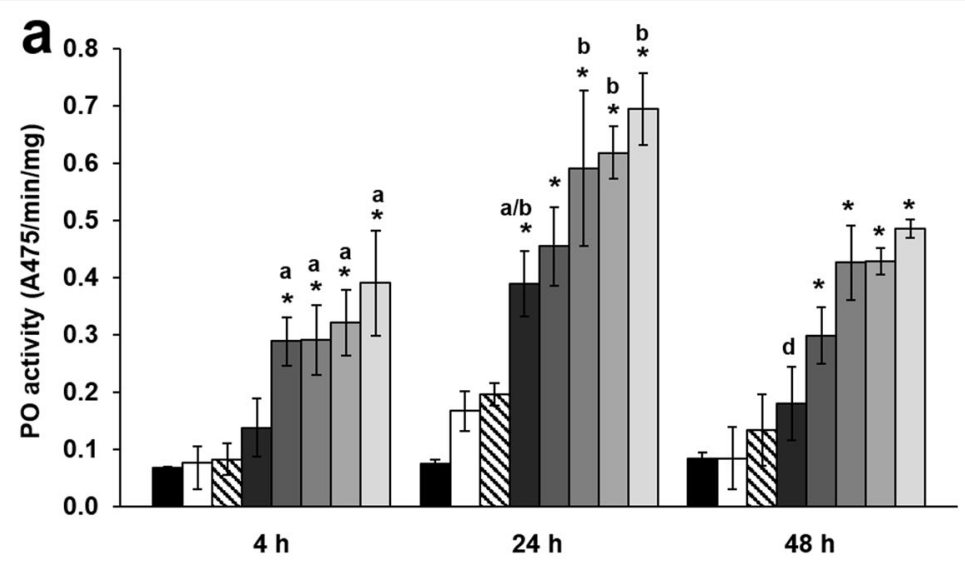

$$
\begin{aligned}
& \square \text { Untouched } \\
& \square \text { PBS } \\
& \square \text { PBS + } 5 \% \text { DMSO }
\end{aligned}
$$

25 ng/larva

$\square 50$ ng/larva

$\square 75 \mathrm{ng} / \mathrm{larva}$

$100 \mathrm{ng} / \mathrm{larva}$

Okadaic acid

$\square 125$ ng/larva

b

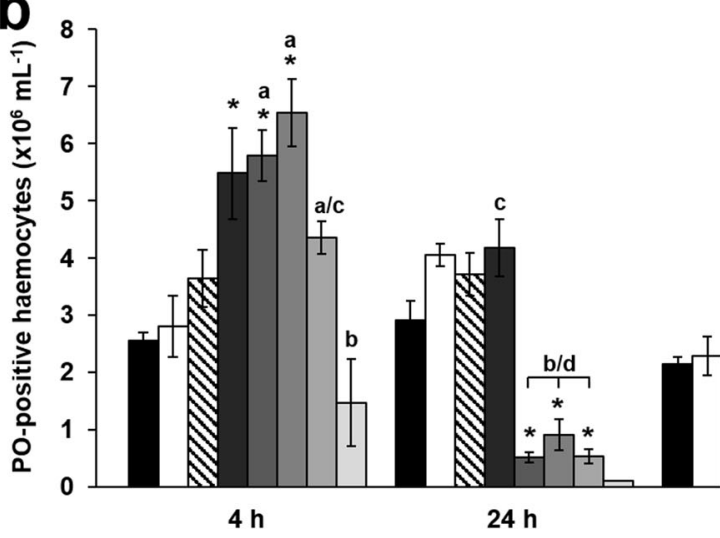

Fig. 3 Phenoloxidase-associated activities in Galleria mellonella injected with increasing concentrations of okadaic acid, 0-125 ng/ larva. a Phenoloxidase (PO) enzyme activities were recorded over a 48-h period. b The numbers of haemocytes staining positively for $\mathrm{PO}$ were recorded over a $48 \mathrm{-h}$ period. All values are represented by the mean \pm SE ( $n=18$ per treatment, 144 in total). An

cuticle (Fig. 4a-c). Conversely, the inoculum remained within the insect gastrointestinal tract (i.e. the midgut) when force-fed and did not appear to leak into the surrounding haemolymph (Fig. 4d-f). Similar to the initial toxicity screening (Fig. 1a), the majority of insect mortalities occurred within $24 \mathrm{~h}$ regardless of the route of OA exposure (Fig. 5), up to $90 \%$ using the highest dose tested (125 ng/larva). $\mathrm{LD}_{50}$ values at $24 \mathrm{~h}$ p.i. were calculated as $252.8 \mu \mathrm{g} / \mathrm{kg}\left[R^{2}=0.900, n=30\right]$ for injected insects and $248.3 \mu \mathrm{g} / \mathrm{kg}\left[R^{2}=0.947, n=30\right]$ for those force-fed. In each case, OA had a significant negative effect on survival when compared to the controls (log-rank (Mantel-Cox) tests, $\chi^{2}(4)=103.6$ and $\chi^{2}(4)=86.35, P<0.0001$ for injection and gavage, respectively). Using a three-way ANOVA, we determined the dose of okadaic acid to account for $83.4 \%$ of the variation $(F(2,24)=70.4, P<0.0001)$, with $<1 \%$ each due to time $(F(1,24)=1.346, P=0.2574)$, and importantly, inoculation method $(F(1,24)=0.1495, P=$ $0.7024)$. No further mortalities were recorded in either force-fed or injected insects at $96 \mathrm{~h}$.

Okadaic acid disrupts gut homeostasis in rodent models leading to tissue damage, cell death, lipid peroxidation, and protein carbonylation (see Table 1). To see if force-feeding the toxin also induced similar symptoms in insect larvae, we measured the activity of the enzymatic antioxidant, superoxide dismutase (SOD), and levels of malondialdehyde (MDA; by-product of lipid peroxidation) in the midgut. OA treatment, particularly doses of 75 and $125 \mathrm{ng} /$ larva, led to significant increases in MDA levels $(F(4,30)=19.6, P<0.0001$; Fig. 6a) and SOD activities $(F(4,30)=30.4$, $P<0.0001$; Fig. 6 b) in the midgut when compared to the PBS control. At $48 \mathrm{~h}$ p.i., SOD activity 


\section{Injection}

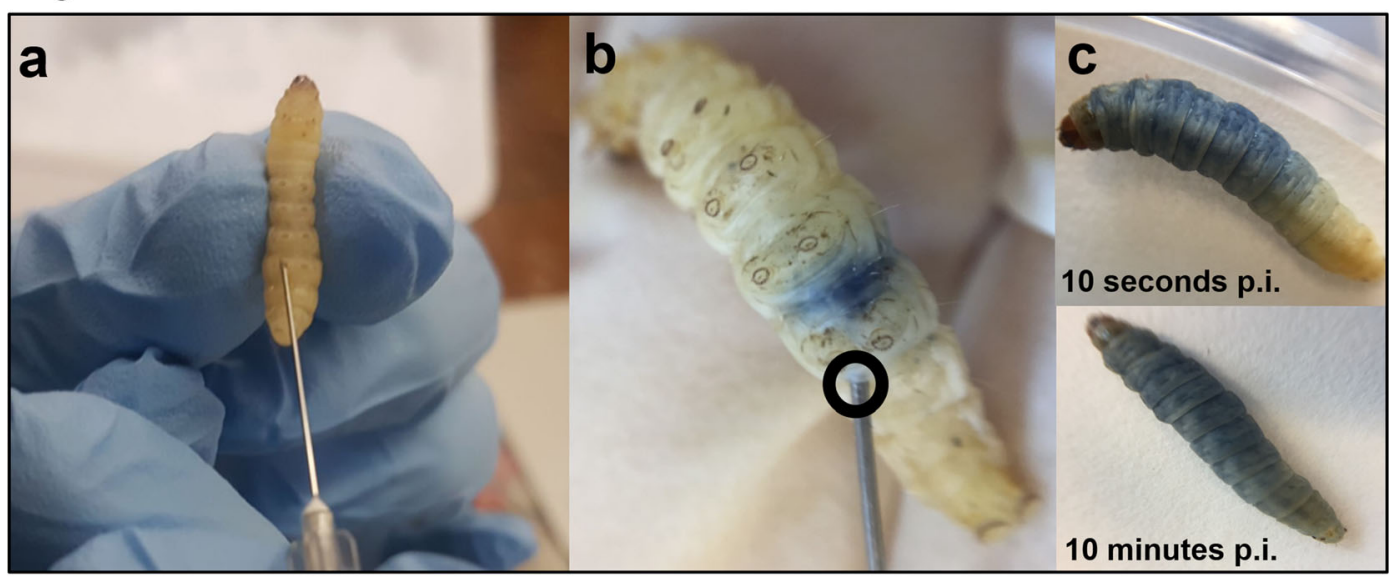

\section{Force feeding}

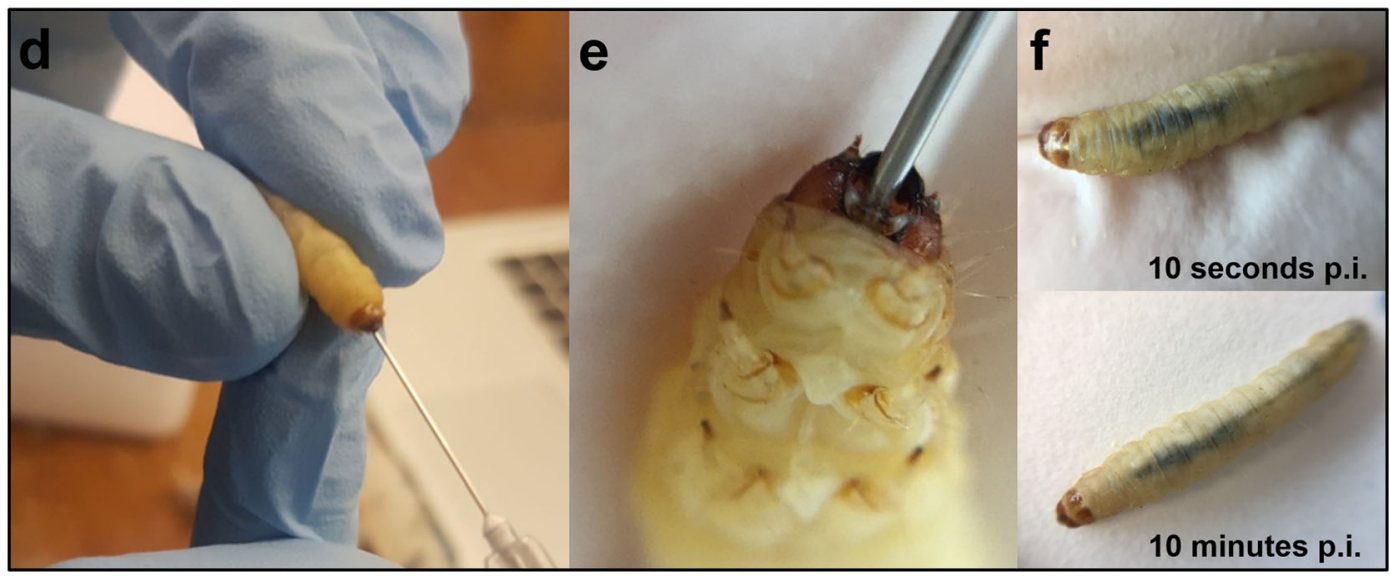

Fig. 4 Administration of okadaic acid via intrahaemocoelic injection and force-feeding (gavage). Images $\mathbf{a}, \mathbf{b}, \mathbf{d}$ and $\mathbf{e}$ depict larvae of Galleria mellonella during inoculation, with $\mathbf{c}$ and $\mathbf{f}$ representing larvae $10 \mathrm{~s}$ and $10 \mathrm{~min}$ post-inoculation (p.i.). To illustrate the distribution of inoculum between the two methods, a solution of $0.4 \%[w / v]$ trypan blue in PBS $\mathrm{pH} 7.4$ was used. The dye $[20 \mu \mathrm{L} /$ larva] remains in the insect gastrointestinal tract (mainly the midgut) when administered orally, whereas the dye disperses when injected directly into the haemocoel (body cavity)

0.048-0.071 Abs $/ \mathrm{mg} / \mathrm{min}$. Although we observed an increase in PO activities in response to oral doses of $\mathrm{OA}$, the levels were not as high as those in insects directly injected with OA (Fig. 3a).

\section{Discussion}

We present clear evidence that G. mellonella larvae exposed to OA have comparable $\mathrm{LD}_{50}$ values to rodent models (Fig. 1, Table 1) and display broad symptoms of immune-cytotoxicity (Figs. 2 and 3) and oxidative damage (Fig. 6). We observed little difference in lethality between force-feeding and injection (Fig. 5); therefore, 


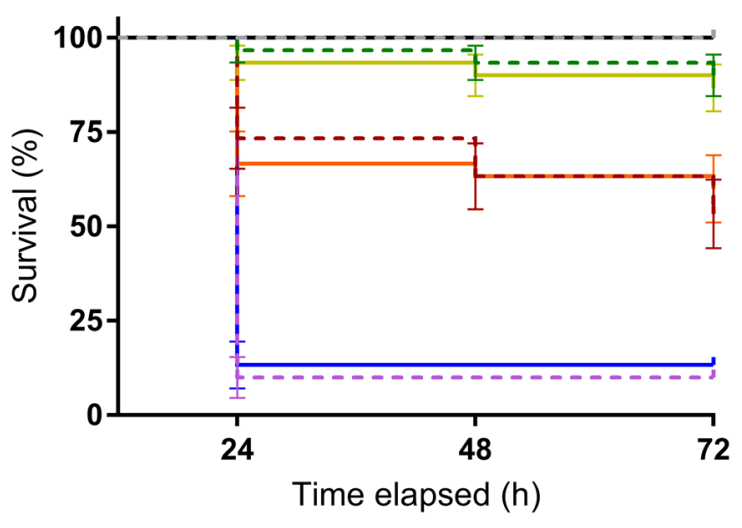

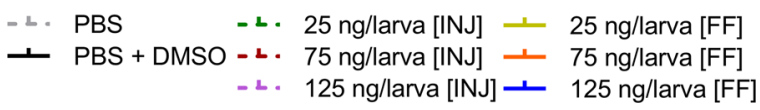

Fig. 5 Okadaic acid intoxication of Galleria mellonella larvae via intrahaemocoelic injection [INJ] and force-feeding [FF]. Survival of $G$. mellonella after exposure to increasing concentrations of okadaic acid $(25,75$, and $125 \mathrm{ng}$ /larva). Post-inoculation, larvae were incubated at $30{ }^{\circ} \mathrm{C}$ in the dark and monitored over a 72-h period. Larvae unresponsive to touch were considered dead. Values are represented by the mean $\pm 95 \%$ CI $(n=30$ per treatment, 300 in total). No mortalities occurred in insects through force-feeding or injection with $20 \mu \mathrm{L}$ phosphate-buffered saline (PBS) or $20 \mu \mathrm{L}$ PBS containing 5\% dimethyl sulfoxide (DMSO)

either administration route would be suitable for screening purposes. Usually, $\geq 3$-fold more OA is needed to induce lethality in rodents force-fed compared to intraperitoneal injection (Munday 2013; Vieira et al. 2013). There is great variation in the toxicity of $\mathrm{OA}$ in mice and rats across the literature, which is influenced not only by the route of inoculation (listed in Table 1), but also by the weight, strain, and sex of the experimental animals, parameters that are not always standardised (Suzuki 2012, 2014). A meta-analysis carried out by Botana et al. (2017) concluded that there is no correlation between $\mathrm{LD}_{50}$ values from intraperitoneal injection and force-feeding OA in vertebrate systems. We recorded differences in larval survival between the initial toxicity screen (Fig. 1, $\mathrm{LD}_{50}=239.6 \mu \mathrm{g} / \mathrm{kg}$ ) and our comparative study (Fig. $5, \mathrm{LD}_{50}=\sim 252.8 \mu \mathrm{g} / \mathrm{kg}$ ), which may be due to the alternative sources of insects used-commercial suppliers versus those reared in-house, respectively. Tsai et al. (2016) stated previously that batch-to-batch variability and environmental parameters (e.g. temperature, nutrients) might result in differential larval survivability between trials. This broad criticism concerning the reproducibility of $G$. mellonella as a model could be resolved with the availability of genetically tractable populations akin to drosophilid resources. We would
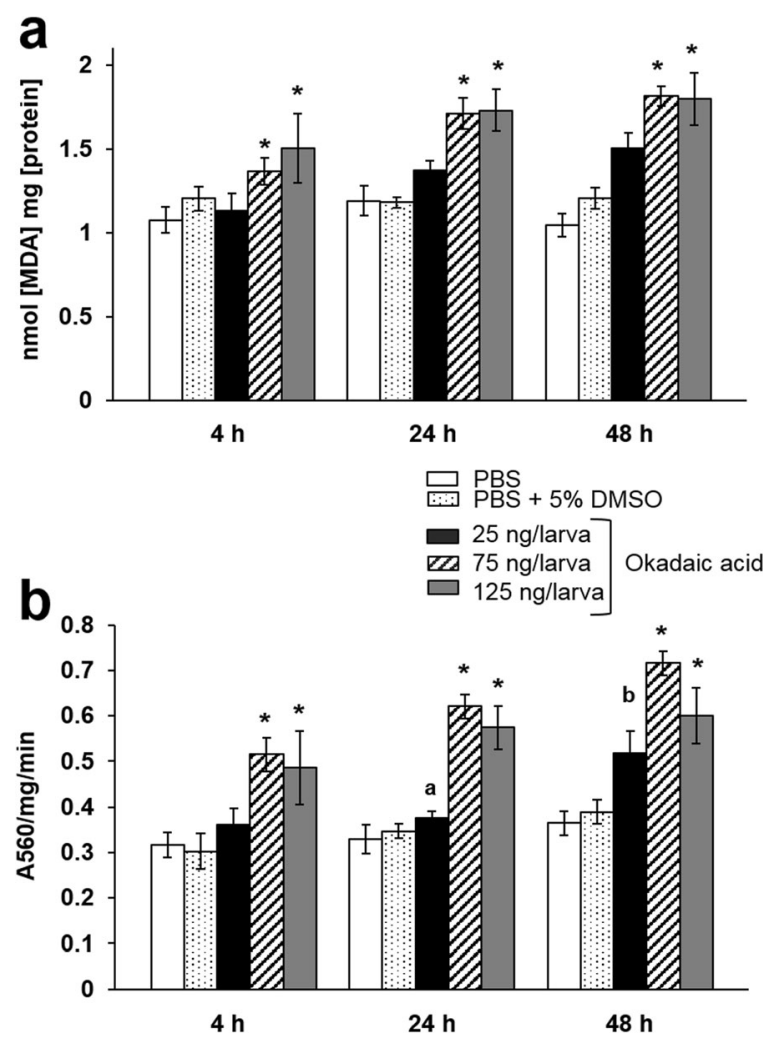

Fig. 6 Oxidative damage in the midgut of Galleria mellonella when force-fed okadaic acid. a Lipid peroxidation was monitored by quantifying malondialdehyde, which is a by-product of oxidative damage. b Enzyme activity of the antioxidant, superoxide dismutase, was quantified over a 48 -h period. An asterisk indicates a significant difference $(P<0.05)$ relative to the PBS control. Unshared letters between the 25-ng/larva treatment at $24 \mathrm{~h}$ and $48 \mathrm{~h}$ represent a significant difference (determined by Tukey's multiple comparisons). All values are represented by the mean \pm SE ( $n=54$ per treatment, 270 in total) for $\mathbf{a}$ and $\mathbf{b}$. It should be noted that extracted midguts from six insects per treatment per time point were pooled

also draw the reader's attention to the likelihood of other endpoints being impacted because of background effects, e.g. immune gene expression, and should be considered carefully when selecting G. mellonella.

Few studies have focussed on the effects of OA on immunity. López et al. (2011) reported on the immuneregulatory properties of OA exposed to T-lymphocytes from the mouse cell line EL-4. Over a 72-h period, OA $(\geq 50 \mathrm{nM}$ ) reduced $\mathrm{T}$ cell receptor complex expression, which is involved in cell sensitivity to antigens. Importantly, OA-induced immunomodulation was mediated by the inhibition of protein phosphatase $2 \mathrm{~A}$. OA is a well-characterised inhibitor of protein phosphatases 1 and $2 \mathrm{~A}$, which has long been considered the cause of 


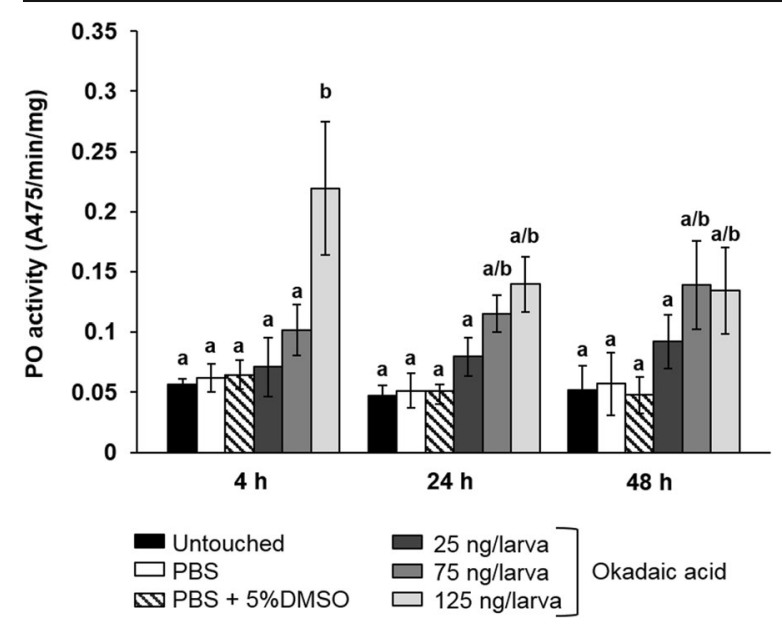

Fig. 7 Phenoloxidase activity in the haemolymph of Galleria mellonella force-fed okadaic acid, 0-125 ng/larva. Phenoloxidase (PO) enzyme activities were recorded over a 48-h period. All values are represented by the mean $\pm \mathrm{SE}$ ( $n=18$ per treatment, 108 in total). Unshared letters represent significant differences determined by Tukey's multiple comparisons $(P<0.05)$

DSP-related symptoms, yet Munday (2013) suggests OA may have several mechanisms of action facilitating its neurotoxicity, immunotoxicity, and genotoxicity. In excess of $100 \mathrm{nM}$, OA can induce apoptosis in human leukocytes in vitro and necrosis at $1000 \mathrm{nM}$ (Valdiglesias et al. 2011). In our study, at the equivalent doses of 100 and $125 \mathrm{ng} /$ larva $(\sim 124-155 \mathrm{nM} \mathrm{OA})$, haemocyte counts reduced by $50 \%$ (Fig. $2 \mathrm{a}$ ), and up to $40 \%$ of the remaining cells were dying/dead (Fig. 2b). Decreases in total haemocyte numbers followed a dosedependent response, yet the highest proportion of dying/ dead cells was observed using $75 \mathrm{ng} /$ larva (Fig. 2). We speculate that OA at $75 \mathrm{ng} /$ larva induces apoptotic cell death whereas higher doses are sufficient to induce necrosis or cytolysis. Trypan blue does not distinguish between early apoptotic (dying) cells and late apoptotic/ necrotic (dead) cells. Okadaic acid also induced sufficient oxidative damage in the midgut that by $48 \mathrm{~h} \mathrm{SOD}$ activities were elevated to assist in detoxification.

Considering shellfish immunity, Prado-Alvarez et al. (2013) exposed clam (Ruditapes decussatus) haemocytes to OA (10-500 nM) and recorded significant increases in cell death and reduced phagocytic capacity within $4 \mathrm{~h}$ in vitro. Mussel (Mytilus galloprovincialis) haemocytes incubated with OA over the same concentration range incurred DNA damage and were functionally compromised (Prego-Faraldo et al. 2015). A transcriptomic survey of OA-treated $M$. galloprovincialis identified 58 mRNAs encoding stress- associated proteins and cellular synthesis (Manfrin et al. 2010). The accumulation of OA in shellfish tissue appears to weaken the immune response, and consequently, they may be more susceptible to disease.

The mechanistic similarities between the innate immune systems of insects and mammals have led to the development of certain insects, e.g. Drosophila melanogaster and G. mellonella, as alternative in vivo models. These species are used successfully to reduce the reliance on vertebrates when assessing microbial and viral infectivity (Ramarao et al. 2012; Champion et al. 2016). Traditionally, microbes and/or toxins are administered by direct injection into the insect body cavity (haemocoel, Fig. 4), and this approach can discriminate between virulent versus non-virulent strains. Two previous studies attempted to develop cockroaches (Nauphoeta cinerea) and/or locusts (Schistocerca gregaria) as bioassays for the detection of saxitoxinthe causative agent of paralytic shellfish poisoning (Ruebhart et al. 2011 and Cook et al. 2006, respectively). The accuracy and/or reliability of this approach is unclear when we consider exposure to shellfish-poisoning toxins is by ingestion.

Maguire et al. (2016) assessed the relative toxicity of common food preservatives (e.g. sodium benzoate) using G. mellonella and found little difference between larvae that were injected or force-fed. Their calculated $\mathrm{LD}_{50}, \mathrm{LD}_{80}$, and $\mathrm{IC}_{50}$ values were in good agreement with data recorded for rats and cultured HEp- 2 cells. The importance of this study is not to be overlooked. When characterising biocides, the route of exposure should be mimicked most closely_particularly when validating results obtained using substitutes to rodents and nonhuman primates, i.e. insect larvae. Over the last decade, the popularity of G. mellonella as a surrogate model of pathobiology and innate immunity has increased substantially and now includes marine pathogens that cause gastroenteritis when they encounter the human gut-Vibrio (Listonella) anguillarum, V. cholerae, and $V$. parahaemolyticus (McMillan et al. 2015; Bokhari et al. 2017; Wagley et al. 2018). The tissue structures and microbiome(s) of the insect gastrointestinal tract are similar to that of mammals (Mukherjee et al. 2013; Maguire et al. 2016, 2017). Many species of gut bacteria, including Firmicutes and Clostridium, are found on the microvilli of the human intestine and insect midgut (Sekirov et al. 2010; Spor et al. 2011; Dubovskiy et al. 2016). Normal gut profiles of 
microbes correlate broadly with disease resistance in humans, and in insects, the resident microbes are regulated by the innate immune system (Koch and Schmid-Hempel 2012). The utility of $G$. mellonella as a gut-specific model has not been investigated fully and offers much potential to explore the inextricable links between immunity, metabolism, and symbionts.

Although no cases of OA-induced mortality exist for humans, concentrations $\geq 75 \mathrm{ng} /$ larva ( $\geq$ $242 \mu \mathrm{g} / \mathrm{kg}$ ) resulted in $>65 \%$ reduction in $G$. mellonella survival, highlighting their possible use as a general screening tool for foodstuffs with suspected contamination of shellfish-poisoning toxins. Furthermore, larvae could be employed to calculate the lethality or cytotoxic potential of marine phytotoxins and their congeners (dinophysistoxin-2, azaspiracids, pectenotoxins, domoic acid, etc.). Identification of toxins still needs to be performed using specialised instruments such as mass spectrometry. Collectively, our evidence suggests $\mathrm{OA}$ is an immune-toxin, affecting blood cell (haemocyte) viability and functionality and leading to uncontrolled levels of PO activity, which generates highly reactive oxygen and nitrosative species as by-products. As PO levels peaked, we detected a corresponding decrease in haemocyte numbers. Even the sublethal dose of $25 \mathrm{ng} /$ larva led to increases in immune cell death within $4 \mathrm{~h}$. This dose also appeared to disrupt gut homeostasis-albeit the response was delayed compared to the higher doses tested, and not statistically significant when compared to the controls. Increasing the dose to $50 \mathrm{ng} /$ larva reduced survival by $25 \%$ within $24 \mathrm{~h}$. Interestingly, $50 \mathrm{ng} / \mathrm{larva}$ is equivalent to $161.3 \mu \mathrm{g} / \mathrm{kg}$, which is the approximate upper regulatory limit for contaminated shellfish tissues $(160 \mu \mathrm{g} / \mathrm{kg})$ set by the Food Standards Agency UK (FSA 2018).

Our data demonstrates clearly the sensitivity of $G$. mellonella larvae to physiologically relevant quantities of OA. We have compared the toxicity of OA in insect larvae to rodent models using $\mathrm{LD}_{50}$ values as a general toxicology endpoint and, in doing so, validated the use of $G$. mellonella as a tool for studying DSP-associated marine toxins. By performing several immunotoxicological assays, we also posit that $\mathrm{OA}$ is a candidate immune-modulator and warrants further investigation.
Acknowledgements Special thanks to Jonathan W. Smellie for gathering some preliminary data and Theo Bennison for his photography skills. We are grateful to the three anonymous reviewers for their constructive comments and insights.

Author contributions C.J.C. conceived the study and designed the experiments. All authors performed the experiments. C.J.C. collated and analysed the data. C.J.C. wrote the manuscript with input from J.L. and A.F.R.

Funding information Operations were part funded by the European Regional Development Fund through the Ireland Wales Cooperation programme, BLUEFISH, awarded to C.J.C. and A.F.R. and Swansea University start-up funds assigned to C.J.C. A KESS2 PhD Scholarship supports H.E. via the European Social Fund.

\section{Compliance with ethical standards}

Conflict of interest The authors declare that they have no conflicts of interest.

OpenAccess This article is distributed under the terms of the Creative Commons Attribution 4.0 International License (http:// creativecommons.org/licenses/by/4.0/), which permits unrestricted use, distribution, and reproduction in any medium, provided you give appropriate credit to the original author(s) and the source, provide a link to the Creative Commons license, and indicate if changes were made.

\section{References}

Aladaileh S, Nair SV, Raftos DA. Induction of phenoloxidase and other immunological activities in Sydney rock oysters challenged with microbial pathogen-associate molecular patterns. Fish Shellfish Immunol. 2007;23:1196-208.

Allegra E, Titball RW, Carter J, Champion OL. Galleria mellonella larvae allow the discrimination of toxic and nontoxic chemicals. Chemosphere. 2018;198:469-72.

Aune T, Larsen S, Aasen JA, Rehmann N, Satake M, Hess P. Relative toxicity of dinophysistoxin-2 (DTX-2) compared with okadaic acid, based on acute intraperitoneal toxicity in mice. Toxicon. 2007;49:1-7.

Aune T, Espenes A, Aasen JAB, Quilliam MA, Hess P, Larsen S. Study of possible combined toxic effects of azaspiracid- 1 and okadaic acid in mice via the oral route. Toxicon. 2012;60: 895-906.

Bergin D, Reeves EP, Renwick J, Wientjes FB, Kavanagh K. Superoxide production in Galleria mellonella hemocytes: identification of proteins homologous to the NADPH oxidase complex of human neutrophils. Infect Immun. 2005;73(7): 4161-70.

Berven G, Sætre F, Halvorsen K, Seglen PO. Effects of the diarrhetic shellfish toxin, okadaic acid, on cytoskeletal 
elements, viability and functionality of rat liver and intestinal cells. Toxicon. 2001;39:349-62.

Bokhari H, Ali A, Noreen Z, Thomson N, Wren BW. Galleria mellonella is low cost and suitable surrogate host for studying virulence of human pathogenic Vibrio cholerae. Gene. 2017;628:1-7.

Botana LM, Hess P, Munday R, Nathalie A, DeGrasse SL, Feeley $\mathrm{M}$, et al. Derivation of toxicity equivalency factors for marine biotoxins associated with bivalve molluscs. Trends Food Sci Technol. 2017;59:15-24.

Browne N, Heelan M, Kavanagh K. An analysis of the structural and functional similarities of insect hemocytes and mammalian phagocytes. Virulence. 2013;4:597-603.

Butt TM, Coates CJ, Dubovskiy IM, Ratcliffe NA. Chapter nineentomopathogenic fungi: new insights into host-pathogen interactions. Adv Genet. 2016;94:307-64.

Champion OL, Wagley S, Titball RW. Galleria mellonella as a model host for microbiological and toxin research. Virulence. 2016;7:840-5.

Cook AC, Morris S, Reese RA, Irving SN. Assessment of fitness for purpose of an insect bioassay using the desert locust (Schistocerca gregaria L.) for the detection of paralytic shellfish toxins in shellfish flesh. Toxicon. 2006;48:662-71.

Dickey RW, Bobzin SC, Faulkner DJ, Bencsath FA, Andrzejewski D. Identification of okadaic acid from a Caribbean dinoflagellate, Prorocentrum concavum. Toxicon. 1990;28:371-7.

Dominguez HJ, Paz B, Daranas AH, Norte M, Franco JM, Fernández JJ. Dinoflagellate polyether within the yessotoxin, pectenotoxin and okadaic acid toxin groups: characterization, analysis and human health implications. Toxicon. 2010;56: 191-217.

Dubovskiy IM, Grizanova EV, Whitten MMA, Mukherjee K, Greig C, Alikina T, et al. Immuno-physiological adaptations confer wax moth Galleria mellonella resistance to Bacillus thuringiensis. Virulence. 2016;7:860-70.

Fallon JP, Reeves EP, Kavanagh K. The Aspergillus fumigatus toxin fumagillin suppresses the immune response of Galleria mellonella larvae by inhibiting the action of haemocytes. Microbiology. 2011;157:1481-8.

Food Standards Agency UK. (2018). Biotoxin and phytoplankton monitoring. Last accessed, 25th July 2018.

Fujiki H, Suganuma M, Suguri H, Yoshizawa S, Ojika M, Wakamatsu K, et al. Induction of ornithine decarboxylase activity in mouse skin by a possible tumor promoter, okadaic acid. Proc Jpn Acad Ser B Phys Biol Sci. 1987;63:51-3.

Gobler CJ, Doherty OM, Hattenrath-Lehmann TK, Griffith AW, Kang Y, Litaker RW. Ocean warming since 1982 has expanded the niche of toxic algal blooms in the North Atlantic and North Pacific oceans. Proc Natl Acad Sci U S A. 2017;114(19):4975-80.

He J, Yamada K, Zou LB, Nabeshima T. Spatial memory deficit and neurodegeneration induced by the direct injection of okadaic acid into the hippocampus in rats. J Neural Transm. 2001;108:1435-43.

Hinder SL, Hays GC, Brooks CJ, Davies AP, Edwards M, Walne $\mathrm{AW}$, et al. Toxic marine microalgae and shellfish poisoning in the British isles: history, review of epidemiology, and future implications. Environ Health. 2011;10:54.

Ito E, Yasumoto T, Takai A, Imanishi S, Harada K. Investigation of the distribution and excretion of okadaic acid in mice using immunostaining method. Toxicon. 2002;40:159-65.
Jorjão AL, Oliveira LD, Scorzoni L, Figueiredo-Godoi LMA, Cristina A, Prata M, et al. From moths to caterpillars: ideal conditions for Galleria mellonella rearing for in vivo microbiological studies. Virulence. 2018;9:383-9.

Koch H, Schmid-Hempel P. Gut microbiota instead of host genotype drive the specificity in the interaction of a natural hostparasite system. Ecol Lett. 2012;15:1095-103.

Lange A, Beier S, Huson DH, Parusel R, Iglauer F, Frick JS. Genome sequence of Galleria mellonella (greater wax moth). Genome Announc. 2018;6:e1220-17.

Le Hégarat L, Jacquin AG, Bazin E, Fessard V. Genotoxicity of the marine toxin okadaic acid, in human Caco-2 cells and in mice gut cells. Environ Toxicol. 2006;21(1):55-64.

Lim J, Coates CJ, Seoane PI, Garelnabi M, Taylor-Smith LM, Monteith $\mathrm{P}$, et al. Characterizing the mechanisms of nonopsonic uptake of Cryptococci by macrophages. J Immunol. 2018;200:3539-46.

López AM, Rodríguez JJG, Mirón AS, Camacho FG, Grima EM. Immunoregulatory potential of marine algal toxins yessotoxin and okadaic acid in mouse T lymphocyte cell line EL-4. Toxicol Lett. 2011;207:167-72.

Maguire R, Duggan O, Kavanagh K. Evaluation of Galleria mellonella larvae as an in vivo model for assessing the relative toxicity of food preservative agents. Cell Biol Toxicol. 2016;32:209-16.

Maguire R, Kunc M, Hyrsl P, Kavanagh K. Caffeine administration alters the behaviour and development of Galleria mellonella larvae. Neurotoxicol Teratol. 2017;64:37-44.

Manfrin C, Dreos R, Battistella S, Beran A, Gerdol M, Varotto L, et al. Mediterranean mussel gene expression profile induced by okadaic acid exposure. Environ Sci Technol. 2010;44: 8276-83.

McMillan S, Verner-Jeffreys D, Weeks J, Austin B, Desbois AP. Larva of the greater wax moth, Galleria mellonella, is a suitable alternative host for studying virulence of fish pathogenic Vibrio anguillarum. BMC Microbiol. 2015;15:127.

Mowlds P, Coates C, Renwick J, Kavanagh K. Dose-dependent cellular and humoral responses in Galleria mellonella larvae following $\beta$-glucan inoculation. Microbes Infect. 2010;12: 146-53.

Mukherjee K, Raju R, Fischer R, Vilcinskas A. Galleria mellonella as a model host to study gut microbe homeostasis and brain infection by the human pathogen Listeria monocytogenes. In: Yellow biotechnology I. Berlin: Springer; 2013. p. 27-39.

Munday R. Is protein phosphatase inhibition responsible for the toxic effects of okadaic acid in animals? Toxins. 2013;5:26785.

Prado-Alvarez M, Flórez-Barrós F, Méndez J, Fernandez-Tajes J. Effect of okadaic acid on carpet shell clam (Ruditapes decussatus) haemocytes by in vitro exposure and harmful algal bloom simulation assays. Cell Biol Toxicol. 2013;29: 189-97.

Prego-Faraldo MV, Valdiglesias V, Laffon B, Eirín-López JM, Méndez J. In vitro analysis of early genotoxic and cytotoxic effects of okadaic acid in different cell types of the mussel Mytilus galloprovincialis. J Toxic Environ Health A. 2015;78:814-24.

Ramarao N, Nielsen-Leroux C, Lereclus D. The insect Galleria mellonella as a powerful infection model to investigate bacterial pathogenesis. J Vis Exp. 2012;(70):e4392. 
Ruebhart DR, Radcliffe WL, Eaglesham GK. Alternative bioassay for the detection of saxitoxin using the speckled cockroach (Nauphoeta cinerea). J Toxic Environ Health A. 2011;74: 621-37.

Sekirov I, Russell SL, Antunes LCM, Finlay BB. Gut microbiota in health and disease. Physiol Rev. 2010;90:859-904.

Spor A, Koren O, Ley R. Unravelling the effects of the environment and host genotype on the gut microbiome. Nat Rev Microbiol. 2011;9:279-90.

Suzuki H. Susceptibility of different mice strains to okadaic acid, a diarrhetic shellfish poisoning toxin. Food Addit Contam Part A. 2012;29:1307-10.

Suzuki H. Influence of body weight of mice on the susceptibility to okadaic acid, a diarrhetic shellfish poisoning toxin. Food Addit Contam Part A. 2014;31:719-22.

Tsai CJY, Loh JMS, Proft T. Galleria mellonella infection models for the study of bacterial diseases and for antimicrobial drug testing. Virulence. 2016;7:214-29.

Tubaro A, Sosa S, Carbonatto M, Altinier G, Vita F, Melato M, et al. Oral and intraperitoneal acute toxicity studies of yessotoxin and homoyessotoxins in mice. Toxicon. 2003;1: 783-92.

Valdiglesias V, Laffon B, Pásaro E, Méndez J. Okadaic acid induces morphological changes, apoptosis and cell cycle alterations in different human cell types. J Environ Monit. 2011;13:1831-40.

Valdiglesias V, Prego-Faraldo MV, Pásaro E, Méndez J, Laffon B. Okadaic acid: more than a diarrheic toxin. Mar Drugs. 2013;11:4328-49.
Vale P, Sampayo MADM. First confirmation of human diarrhoeic poisonings by okadaic acid esters after ingestion of razor clams (Solen marginatus) and green crabs (Carcinus maenas) in Aveiro lagoon, Portugal and detection of okadaic acid esters in phytoplankton. Toxicon. 2002;40:989-96.

Vieira AC, Rubiolo JA, López-Alonso H, Cifuentes JM, Alfonso A, Bermúdez R, et al. Oral toxicity of okadaic acid in mice: study of lethality, organ damage, distribution and effects on detoxifying gene expression. Toxins (Basel). 2013;5:2093108.

Wagley S, Borne R, Harrison J, Baker-Austin C, Ottaviani D, Leoni F, et al. Galleria mellonella as an infection model to investigate virulence of Vibrio parahaemolyticus. Virulence. 2018;9:197-207.

Whitten M, Coates CJ. Re-evaluation of insect melanogenesis research: views from the dark side. Pigment Cell Melanoma Res. 2017;30(4):386-401.

Wuensch A, Trusch F, Iberahim NA, Van West P. Galleria mellonella as an experimental in vivo host model for the fish-pathogenic oomycete Saprolegnia parasitica. Fungal Biol. 2018;122:182-9.

Yasumoto T, Murata M, Oshima Y, Sano M, Matsumoto GK, Clardy J. Diarrhetic shellfish toxins. Tetrahedron. 1985;41: 1019-25.

Zhang Z, Simpkins JW. An okadaic acid-induced model of tauopathy and cognitive deficiency. Brain Res. 2010;1359: 233-46. 